Article

\title{
Social Capital, Human Capital, and Sustainability: A Bibliometric and Visualization Analysis
}

\author{
Fernando J. Garrigos-Simon ${ }^{1}$, M. Dolores Botella-Carrubi ${ }^{2}(\mathbb{D})$ and Tomas F. Gonzalez-Cruz ${ }^{3, * \mathbb{C}}$ \\ 1 Departamento de Organización de Empresas, Universitat Politècnica de València, 46022 Valencia, Spain; \\ fgarrigos@doe.upv.es \\ 2 INEDE Business School, Catholic University of Valencia 'San Vicente Martir', 46008 Valencia, Spain; \\ dolores.botella@ucv.es \\ 3 Business Department, University of Valencia, 46022 Valencia, Spain \\ * Correspondence: tomas.gonzalez@uv.es
}

Received: 28 October 2018; Accepted: 8 December 2018; Published: 13 December 2018

check for updates

\begin{abstract}
Academic interest in social and human capital is growing significantly. Similarly, their relationship with sustainability is increasing, especially compared to sustainability's relationship with natural capital and financial and economic capital. Bibliometric and visualization research on these relationships is nonetheless insufficient. This study analyzes the evolution of the literature on natural capital, financial and economic capital, and social and human capital related to sustainability. On the other hand, the study presents a bibliometric analysis on social capital and human capital (SHC) related to sustainability. The article studies 635 references collected from the Web of Science (WoS) Core Collection database and utilizes visualization of similarities (VOS) viewer program to graphically map the material. The analysis involves co-occurrence of keywords, co-citation, and co-authorship. The results reveal not only the state of the art and the leading trends, but also the evolution regarding impact, main journals, documents, topics, authors, institutions, and countries. The study provides researchers and practitioners with a visual and schematic frame of the research on this topic.
\end{abstract}

Keywords: social capital; human capital; bibliometrics; visualization

\section{Introduction}

Social and human capital (SHC) has become an important research topic. The aim of this study is to analyze the leading trends on sustainability, specifically the literature that has connected SHC with sustainability in recent decades. Social capital was initially defined as "the aggregate of the actual or potential resources which are linked to possession of a durable network of more or less institutionalized relationships of mutual acquaintance or recognition" [1] (p. 248). The concept is also defined as "a resource that actors derive from specific social structures and then use to pursue their interests; it is created by changes in the relationship among actors" [2] (p. 619), and as "the ability of actors to secure benefits by virtue of membership in social networks or other social structures" [3] (p. 6). More recently, Falk and Kilpatrick (2000) defined the concept as "an accumulation of the knowledge and identity resources drawn on by communities-of-common-purpose" [4] (p. 87). Despite the wide variety of definitions, social capital's concern is clear: the benefits of social connectedness in diverse communities and the relevance of social networks for the development of resources and skills. Social capital also includes the idea that social bonds and social norms are the basis of sustainable livelihoods [5], hence its importance as a template for personal and collective evaluation of changes [6]. Furthermore, social capital may have a relevant role in the management of resources such as natural resources in diverse socio-economic and cultural contexts [7]. 
On the other hand, human capital refers to the capital provided by employees or individuals. Coleman (1988) states that "human capital is created by changes in persons that bring about skills and capabilities that enable them to act in new ways" [8] (p. 100). Similarly, human capital also refers to the know-how, information, relationships, and general capabilities that individuals provide to the firm through the employment relationship [9], or to "a set of abilities and skills obtained because of training, as well as the scientific activities of workers necessary for the effective operation of the enterprise" [10] (p. 121). This type of capital "comprises all the knowledge assets (tacit and explicit) placed in individuals" [11] (p. 333). In sum, human capital is necessary to apply and develop knowledge in the firm [12].

The relevance of both concepts is reflected in a significant increase of research on these topics. This is explained by sustainability's generally positive effect on social, human, and natural capital. In contrast, unsustainable behaviors tend to deplete these assets, leaving fewer for future generations [13]; on the other hand, several authors, such as Bebbington and Perreault [14], conceptualize sustainable development in terms of some types of capital, and explore ways in which social and human capital (and also financial, physical or natural capital) contribute to theoretical frameworks in sustainable development. Specifically, these authors draw out some of the links among social capital formation, the access to other capitals, or the development of livelihood, political change, and the transformation of the landscape. However, the particulars of the research on SHC are unknown, especially in the case of research related to sustainability. Following the structure of the Special Issue, which considers human capital as a part of the broad term of social capital, and which could in turn include "societal capital", and due to the lack of enough data to analyze them separately, we analyze both terms together. In addition, and following the structure of the Special Issue, we compare financial and economic capital, social and human capital, and natural capital.

A common technique to analyze research output is bibliometrics, a cross-disciplinary science that studies the bibliographic data through mathematical and statistical tools $[15,16]$. The technique is recognized because of its potential to use objective information [17] and the possibility to analyze specific research areas and obtain relevant conclusions [18]. Some studies analyze the structure of research on sustainability. For instance, Garrigós et al. (2018) offer a review of diverse bibliometric analyses regarding sustainability and management, marketing, and fields related to innovation, information technology, logistics, and economics.

Other bibliometric studies analyze research on social capital related to management [19], communication [20], sociology [21], or academic careers [22]. In addition, some bibliometric studies focus on human capital [23] or related areas such as non-financial information [24] and human capital in university research centers [25]. Additionally, some bibliometric analyses focus on the combination of social and human capital [26] in academic research on science and engineering [27]. In fact, bibliometric research has even analyzed social capital related to sustainable forest management [28]. However, there is a lack of bibliometric or visualization analyses on SHC in general, or on SHC's relationship to sustainability despite their relevance for practitioners and researchers. This analysis provides an overview of the study of SHC and sustainability and a visualization of the structure and development of this kind of research. On the one hand, researchers can identify key ideas for future research. On the other hand, managers can understand better the situation of SHC and its relationship with sustainability issues.

Given the relevance of bibliometric analyses and SHC related to sustainability, and the lack of appropriate bibliometric and visualization studies, this study provides an in-depth and updated bibliometric analysis of the evolution of SHC literature related to sustainability. The research comprises 635 documents, drawn from the Web of Science (WoS) database, and the use of the visualization of similarities (VOS) viewer software to graphically map the data. Co-occurrence of keywords, co-citation and co-authorship tools are employed.

The results indicate the important development of the literature on sustainability and on SHC related to sustainability in recent decades. Furthermore, although the literature about financial and 
economic capital, and natural capital related to sustainability has been growing significantly over the last few years, its development is still incipient. Focusing on SHC related to sustainability, the study shows that the main studies on the topic, led by Folke et al. (2005), are highly cited, which confirms the relevance of the topic [29]. The journals that have published the most on these topics are Sustainability, Ecological Economics, and Journal of Cleaner Production; the most-cited documents among the 635 works are authored by Putnam, Coleman, and Pretty; and the journal whose documents are cited the most is World Development. The study shows that there are some prevailing approaches to the topic, such as managerial, economic, tourism, and sociological perspectives, although the multidisciplinarity of some clusters indicates the growing potential of this area.

According to the results, the main institutions that published documents on the topic are from Anglo-Saxon countries such as the USA, England, and Australia. Conversely, studies from India or China are very sparse. The results are especially important for practitioners and policymakers, since the results identify important topics of the literature on the subject and the main trends. The indicators used in the study allow identifying the goals of the studies, such as the development of appropriate polices, or sustainable management of institutions. The reason is that they have to incorporate not only the main research findings, but also the incipient trends if their aim is to develop sustainable policies. The study also suggests the incorporation of diverse perspectives related to information and communication technologies, collaborative economy, or ethical and socially responsible corporate policies in the development of managerial policies. As for research, the study stresses the knowledge about SHC related to sustainability and plots the connections among the diverse authors, institutions and perspectives, being also a source of new ideas for the development of future research. These ideas can be developed after considering the state of the art, the pioneer trends, the perspectives that have not been analyzed yet in the literature, the trends that are showing a more rapid expansion, or the explanation offered for the development of the diverse trends.

The structure of the article is as follows. Section 2 explains the data sources and bibliometric methods used, Section 3 provides the bibliometric and graphic results, and Section 4 comprises the discussion and main conclusions.

\section{Materials and Methods}

This study uses data from the WoS Core Collection database, a platform that includes various sub-databases. WoS is one of the two most popular and widely recognized international databases. This dataset is selected because it only incorporates the journals with the highest standards [30]. Other important datasets, such as Google Scholar, are criticized for their unreliability [31]. Our selection follows the procedure in Cancino et al. [32] and Garrigos et al. [16] in recent bibliometric analyses.

In order to focus only on SHC material, the results were filtered using the keywords "social capital" and "sustainability" simultaneously, or "human capital" and "sustainability", also simultaneously, for all the knowledge areas in the WoS [33]. The population comprises all documents published until the 31 December, 2017. Data collection took place in June 2018. The final sample was limited to articles, reviews, letters, and notes [16,32]. Thus, the sample includes only 635 documents.

With the aim of analyzing and representing the data, the article uses some of the most popular bibliometric indicators. Specifically, the number of documents is used to assess productivity, while the number of citations provides insights into the relevance of an author, institution or country in that area [30,34]. Additionally, the h-index indicates the quality of a set of documents [35] (the h-index of an author indicates that this author has at least $h$ documents cited at least $h$ times [18]). Other indicators are the number of documents above a citation threshold, to observe the influence of the documents [32]; the ratio citations/documents, to quantify the impact of each document; and the impact factor offered by the WoS, to measure journals' dissemination power [33].

Apart from the bibliometric indicators, this research uses science mapping: the VOS viewer software [36]. This software, widely used in bibliometric research [16], employs bibliometric maps to show the structure and networks of authors, journals, universities, or countries. In this case, we studied 
the co-occurrence of author keywords (keywords that appear below the abstract); co-authorship (the number of co-authors among the most productive sources) [32]; and co-citation [37] (two articles receiving a citation from the same document). This procedure follows the most relevant studies in the bibliometric literature [16].

\section{Results}

This study involves six analyses. The first focuses on the state of the art and the progress in the literature on SHC and sustainability, and the situation of other related literature such as financial and economic capital and natural capital in sustainability research. This section also analyzes the citation structure of the documents. The second analysis focuses on the most-cited documents on SHC. The third analysis involves the leading journals. The fourth analysis studies the co-occurrence analysis of author keywords in SHC. The fifth explores the co-citation of references, journals, and authors regarding SHC. Finally, the sixth analysis examines the co-authorship networks of countries and institutions.

\subsection{Status and Evolution of Social and Human Capital, Natural Capital and Financial and Economic Capital in} the Sustainability Literature

Although the first document related to sustainability appeared in the Web of Science (WoS) in 1933, regular publications began around the 1980s. Nevertheless, research has increased exponentially over the last decade, reaching over 10,000 documents a year since 2015 (Figure 1). Following this trend, the literature regarding social and human capital, natural capital, and recently financial and economic capital, progressively focused also on sustainability aspects. Apart from social and human capital, which could be related to "a flow of mutually beneficial collective action, contributing to the cohesiveness of people in their societies" and "the total capability residing in individuals, based on their stock of knowledge skills, health and nutrition", respectively [13] (p. 452); natural capital relates to environmental goods and services (ibid.), including both natural resources and ecosystem services. In addition, economic or, specifically, financial capital "represents accumulated claims on goods and services, built up through financial systems" (ibid.), including tangible and intangible assets. Focusing on the connection between these concepts and sustainability, two studies were published in 1992: one on SHC related to sustainability and another on natural capital related to sustainability. This publication was not sporadic; throughout the 1990s, publications on SHC and natural capital related to sustainability appeared regularly. This trend was followed by documents related to financial and human capital a decade later. The first documents related to financial or economic capital and sustainability appeared in 2003, and the publications have increased regularly since then. Another important trend is the diverse evolution of these three areas of research related to sustainability. Therefore, research on natural capital increased significantly over the 20th century, but as that research field began to lose relevance, SHC literature gained momentum. In particular, research on SHC is double the amount of research on natural capital and is ten times more exhaustive than research on financial and economic capital. This fact justifies the approach followed in this study. The lack of research on financial and economic capital related to sustainability, and the insignificant evolution of the literature on natural capital related to sustainability in recent years impedes the performance of an appropriate bibliometric analysis that includes the three research areas. Figure 1 illustrates the annual trends of publications. 


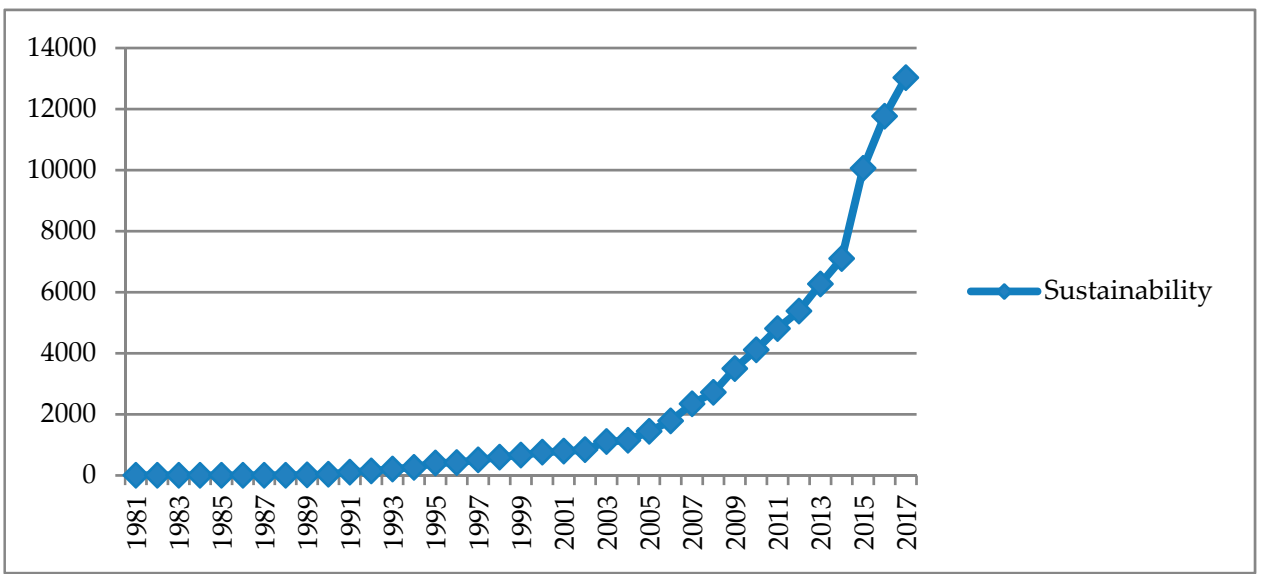

(a)

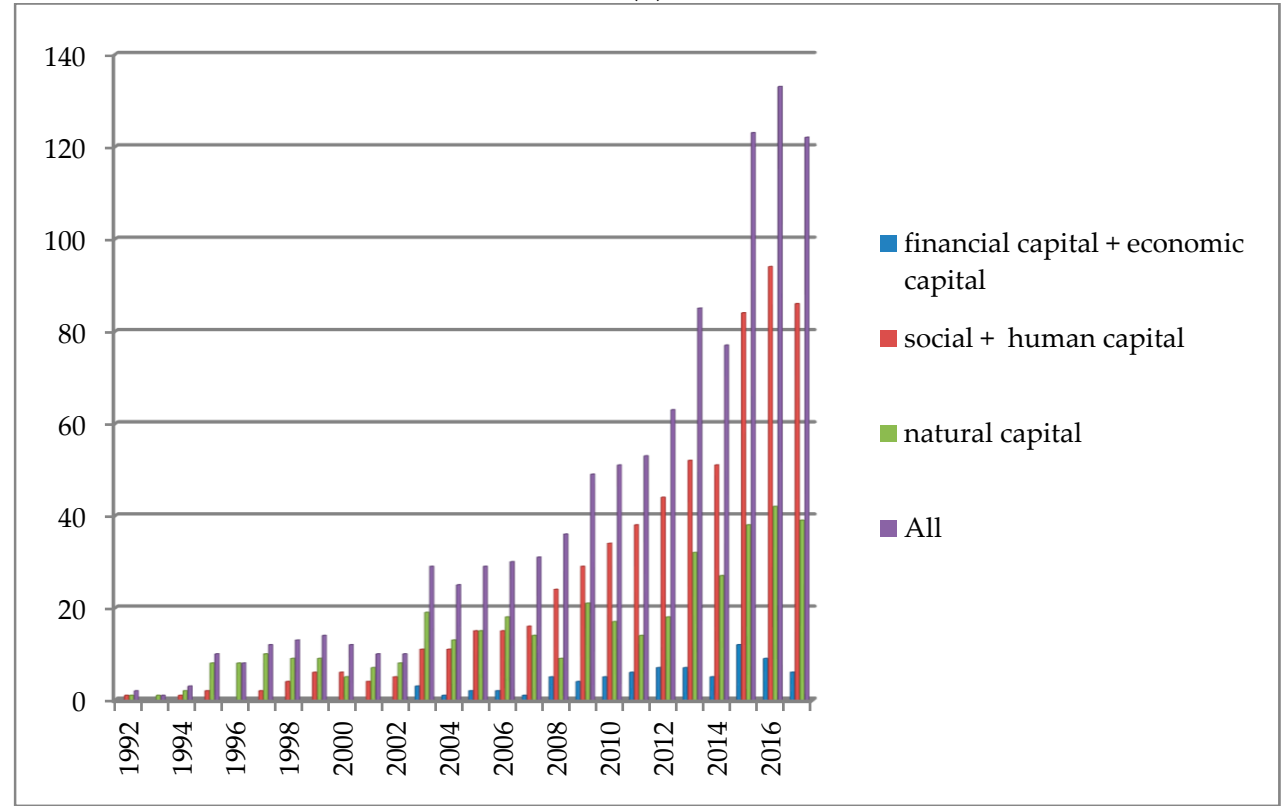

(b)

Figure 1. (a) Annual publications in Web of Science (WoS): Publications on sustainability. (b) Annual publications in WoS: Publications on financial and economic capital related to sustainability, social and human capital related to sustainability, and natural capital related to sustainability. Source: Web of Science.

The dark blue line in the first plot shows the number of publications per year in WoS on sustainability. In the second graph, the blue bars indicate the annual research on financial and economic capital related to sustainability according to the results of a search performed using the keywords "financial capital" and "sustainability" as well as "economic capital" and "sustainability" simultaneously, for all the knowledge areas in the WoS; the red bars represent the documents on social and human capital related to sustainability, and the green bars, the annual research about natural capital related to sustainability. This result reflects the search using the keywords "natural capital" and "sustainability", in all the knowledge areas of the WoS. The purple bars represent the combined output of these three research areas.

Citation analysis shows the relevance of the documents published in the selected areas. In this vein, the most-cited document on sustainability is authored by Yusuf Chisti [38], with more than 4100 citations. Regarding SHC related to sustainability, the most-cited document is an article by Folke et al. [29], with more than 1700 citations (almost 150 citations per year). 
Table 1 shows the general citation structure of research on SHC related to sustainability. Three documents have more than 500 citations $(0.47 \%), 3.62 \%$ of the articles have more than 50 citations, and $18.58 \%$ of the documents have 10 citations or more. In addition, the h-index [35] for these documents is 48 ( 48 documents have 48 or more citations). This index is important because it offers an overview of the area [33].

Table 1. General citation structure in social and human capital (SHC) related to sustainability.

\begin{tabular}{ccccc}
\hline $\begin{array}{c}\text { Number of } \\
\text { Citations }\end{array}$ & $\begin{array}{c}\text { Number of } \\
\text { Articles }\end{array}$ & $\begin{array}{c}\text { Accumulated N. } \\
\text { of Articles }\end{array}$ & \% Articles & $\begin{array}{c}\text { \% Accumulated } \\
\text { Articles }\end{array}$ \\
\hline$\geq 500$ & 3 & 3 & 0.47 & 0.47 \\
$\geq 250$ & 2 & 5 & 0.31 & 0.79 \\
$\geq 100$ & 19 & 24 & 2.99 & 3.78 \\
$\geq 50$ & 23 & 47 & 3.62 & 7.40 \\
$\geq 25$ & 50 & 97 & 7.87 & 15.28 \\
$\geq 10$ & 118 & 215 & 18.58 & 33.86 \\
$<10$ & 420 & 635 & 66.14 & 100.00 \\
\hline Total & 635 & & & \\
\hline
\end{tabular}

Source: Own elaboration based on WoS 2017.

\subsection{Main Cited Papers in SHC Related to Sustainability}

Regarding the most influential documents on SHC related to sustainability, Table 2 presents the top 24 documents with the most citations (documents with more than 100 citations). The analysis of the number of citations indicates not only the quality of a publication, but also its popularity and influence within a research field [16].

Table 2. Top 24 documents with the most citations (more than 100) in SHC.

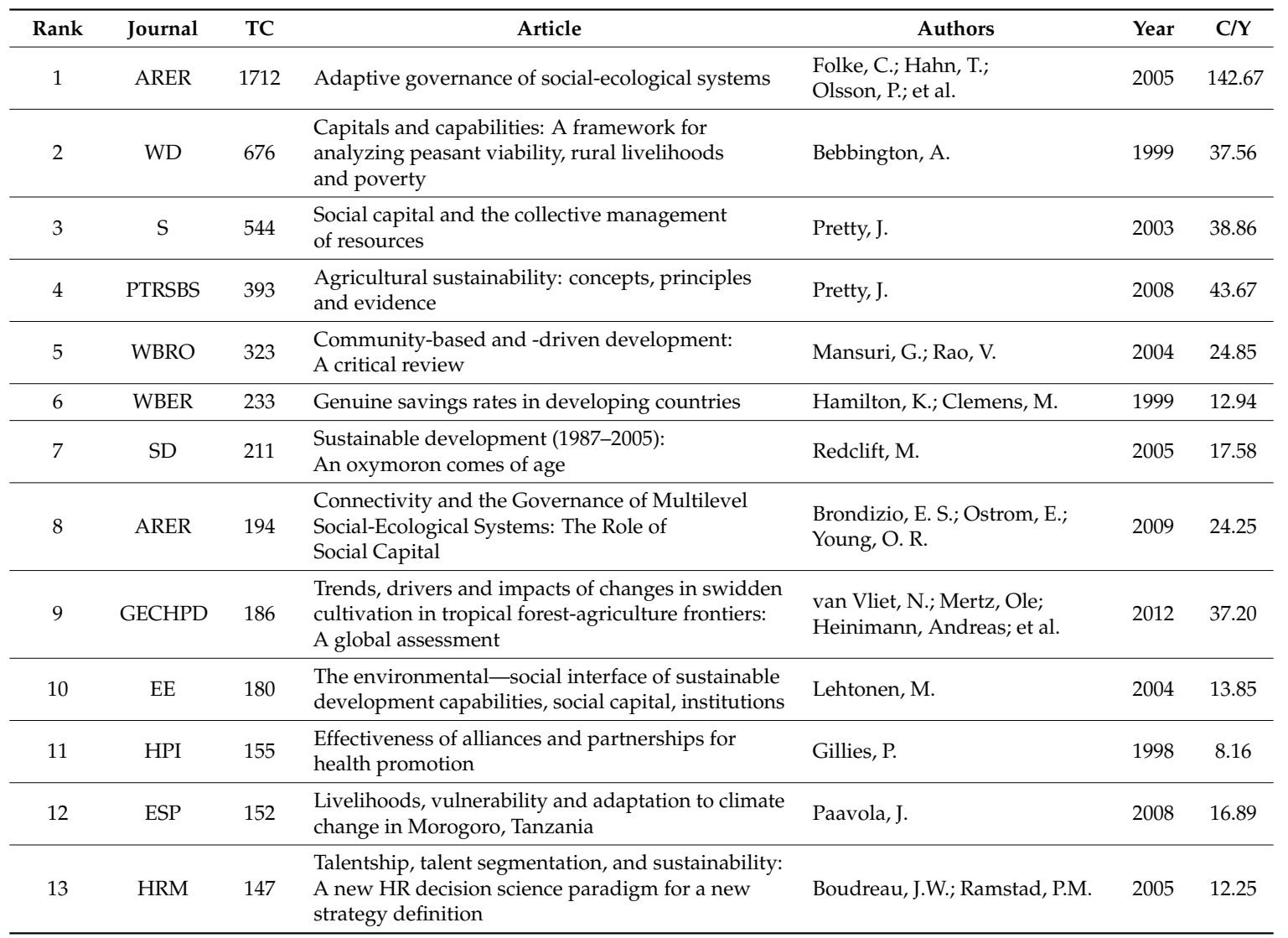


Table 2. Cont.

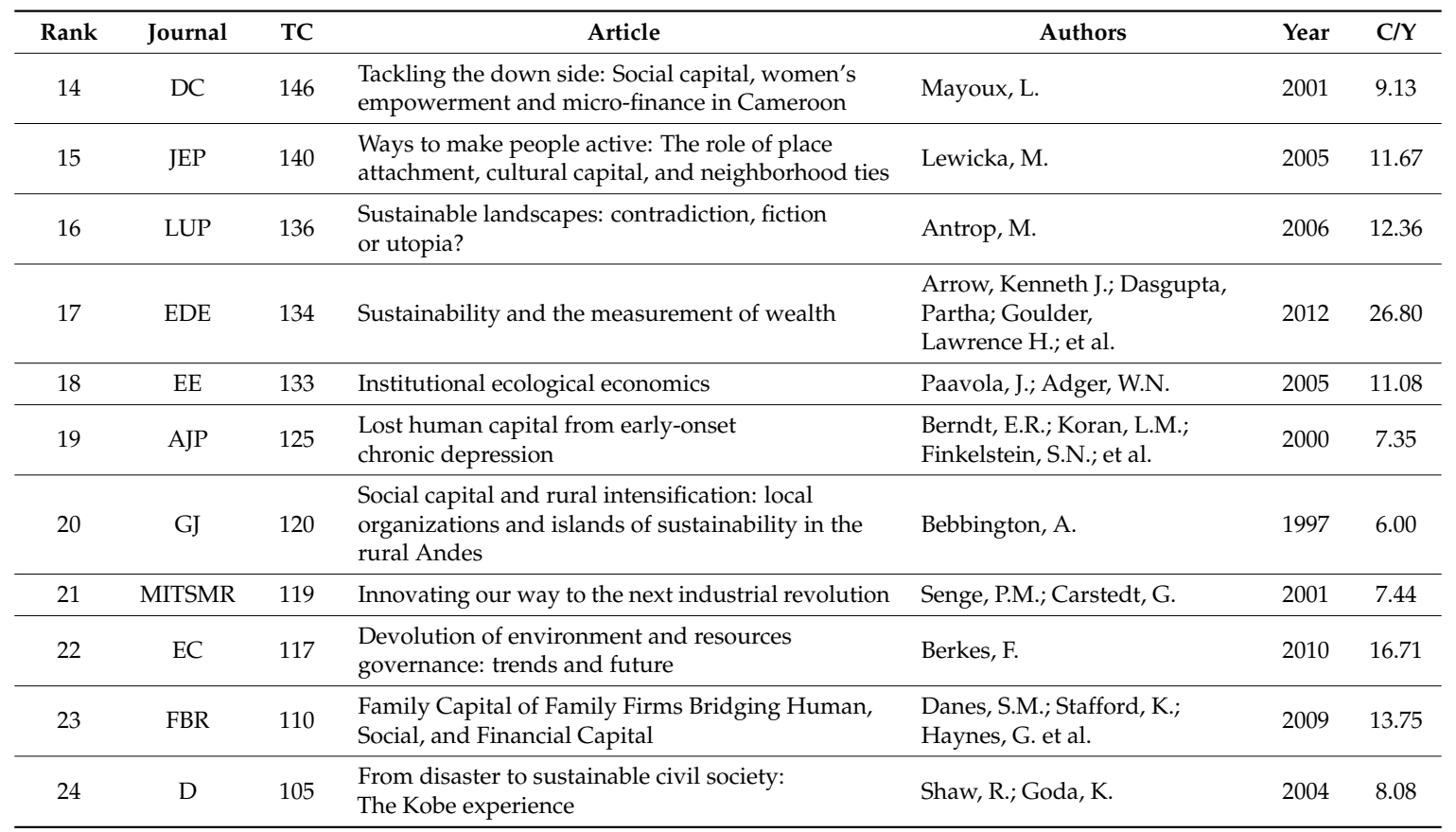

Source: Own elaboration based on WoS 2017. R: Ranking; TC: Total Citations; C/Y: Citations per year. ARER: Annual Review of Environment and Resources; WD: World Development; S: Science; PTRSBS: Philosophical Transactions of the Royal Society B-Biological Sciences; WBRO: World Bank Research Observer; WBER: World Bank Economic Review; SD: Sustainable Development; ARER: Annual Review of Environment and Resources; GECHPD: Global Environmental Change-Human and Policy Dimensions; EE: Ecological Economics; HPI: Health Promotion International; ESP: Environmental Science \& Policy; HRM: Human Resource Management; DC: Development and Change; JEP: Journal of Environmental Psychology; LUP: Landscape and Urban Planning; EDE: Environment and Development Economics; AJP: American Journal of Psychiatry; GJ: Geographical Journal; MITSMR: MIT Sloan Management Review; EC: Environmental Conservation; FBR: Family Business Review; D: Disasters.

The article by Folke et al. (2005) ranks first in number of citations (1712) and in number of citations per year (142.67). That article analyzes the social dimension that enables adaptive ecosystem-based management and governance [29]. The results highlight that the management of ecosystem and landscapes is complex; however, legislation and governmental policies can support it. The other two documents with the most citations are the one by Bebbington (1999), with 676 citations, and the article by Pretty (2003), with 544 citations. However, second in the number of citations per year is another article by Pretty (2008), with 43.67 citations per year. The classical study by Bebbington (1999) develops an analytical framework for studying rural livelihoods in terms of sustainability and implications for rural poverty. The study highlights the relevance of social capital as an important asset through which people can widen access to resources and other actors [39]. The article by Pretty focuses on the collective management of resources, analyzes the concept of social capital, and stresses the critical importance of social bonds and norms for sustainability. The article stresses the relevance of investing in collective activities, which can offer a route to sustainable management and governance of common resources [40]. Finally, Pretty reviews agricultural sustainability and focuses on people's collective capacities and human capital to solve problems and promote sustainability; specifically, the paper stresses the need for new approaches to improve people's collective capacities to solve common resource problems, and to understand the benefits of ecological and agronomic management, manipulation, and redesign [13]. The rest of the documents are very diverse in authorship and content.

\subsection{Leading Journals in SHC Related to Sustainability}

The 635 documents about SHC related to sustainability were published in 436 journals. The main categories of publications were environmental studies (141 documents, 22.17\%), environmental sciences 
(124 documents, 19.50\%), economics (91 documents, 14.31\%), green sustainable science technology (76 documents, $11.95 \%$ ) and planning development (73 documents, $11.48 \%$ ).

Regarding the sources, $70.59 \%$ published only one document, 13 published five or more, four sources published more than 10 documents, and only two sources published more than 20 documents. The top five journals published $12.42 \%$ (79) of all the documents, and the top 10 journals published $17.77 \%$ of all documents (121) (Table 3). Specifically, the top three sources regarding publications on SHC related to sustainability were: Sustainability (3.93\%), Ecological Economics (3.30\%), and the Journal of Cleaner Production (2.04\%). Nevertheless, the h-index is led by Ecological Economics (13) and the Journal of Cleaner Production (10).

Table 3. The top journals with SHC publications.

\begin{tabular}{|c|c|c|c|c|c|c|c|c|c|c|c|c|c|}
\hline Rank & Journal & APSHC & H-SHC & TAP & TCSHC & ACSHC & PCSHC & \%APSHC & IF & $\geq 200$ & $\geq 100$ & $\geq 50$ & $\geq 20$ \\
\hline 1 & $S$ & 25 & 5 & 5579 & 87 & 83 & 3.48 & 0.45 & 1.79 & & & & 0 \\
\hline 2 & $\mathrm{EE}$ & 21 & 13 & 4263 & 702 & 682 & 33.43 & 0.49 & 2.97 & & 2 & 5 & 9 \\
\hline 3 & JCP & 13 & 10 & 9294 & 291 & 285 & 22.38 & 0.14 & 5.72 & & & 1 & 5 \\
\hline 4 & ES & 12 & 6 & 1833 & 201 & 196 & 16.75 & 0.65 & 2.84 & & & & 5 \\
\hline 5 & JRS & 8 & 6 & 1568 & 147 & 145 & 18.38 & 0.51 & 2.38 & & & 1 & 2 \\
\hline 6 & SNR & 8 & 5 & 1714 & 77 & 77 & 9.63 & 0.47 & 1.53 & & & & 1 \\
\hline 7 & $\mathrm{SD}$ & 7 & 5 & 559 & 345 & 327 & 49.29 & 1.25 & 2.17 & 1 & 1 & 2 & 3 \\
\hline 8 & WD & 7 & 6 & 5574 & 851 & 845 & 121.57 & 0.13 & 2.85 & 1 & 1 & 2 & 4 \\
\hline 9 & IJSDWE & 6 & 3 & 996 & 52 & 52 & 0.31 & 0.60 & 1.86 & & & & 1 \\
\hline 10 & JST & 6 & 4 & 634 & 55 & 52 & 9.17 & 0.95 & 2.98 & & & & 1 \\
\hline 11 & GECHPD & 5 & 4 & 1518 & 219 & 219 & 43.80 & 0.33 & 6.33 & & 1 & 1 & 1 \\
\hline 12 & IJAS & 5 & 3 & 278 & 24 & 22 & 4.80 & 1.80 & 1.78 & & & & 0 \\
\hline 13 & SS & 5 & 3 & 389 & 26 & 26 & 5.20 & 1.29 & 3.43 & & & & 0 \\
\hline 14 & BRI & 4 & 3 & 1089 & 99 & 99 & 24.75 & 0.37 & 3.14 & & & & 3 \\
\hline 15 & CIT & 4 & 3 & 571 & 42 & 41 & 10.50 & 0.70 & 2.45 & & & & 1 \\
\hline 16 & GJ & 4 & 3 & 1707 & 138 & 138 & 34.50 & 0.23 & 3.13 & & 1 & 1 & 1 \\
\hline 17 & JEM & 4 & 4 & 7735 & 61 & 61 & 15.25 & 0.05 & 4.01 & & & & 1 \\
\hline 18 & LUP & 4 & 3 & 2749 & 41 & 41 & 10.25 & 0.15 & 3.09 & & & & 0 \\
\hline 19 & LE & 4 & 2 & 260 & 6 & 6 & 1.50 & 1.54 & - & & & & 0 \\
\hline 20 & OCM & 4 & 3 & 2430 & 40 & 40 & 0.47 & 0.16 & 1.86 & & & & 1 \\
\hline
\end{tabular}

Source: Own elaboration based on WoS 2017. R: Ranking; H-SHC: indicates the h-index in the area of Social and Human Capital; APSHC: Articles published on SHC; TAP: Total articles published; TCSHC: Total citations on SHC: ACSHC Articles which are cited on SHC; PCSHC: Average of cites by articles on SHC. \%APSHC: Percentage of documents published on SHC (APSHC/TAP); IF: Impact Factor; $\geq 200, \geq 100, \geq 50$, and $\geq 20$ : documents with more than 200, 100, 50, and 20 citations. S: Sustainability; EE: Ecological Economics; JCP; Journal of Cleaner Production; ES; Ecology and Society; JRS: Journal of Rural Studies; SNR; Society $\mathcal{E}$ Natural Resources; SD: Sustainable Development; WD; World Development; IJSDWE: International Journal of Sustainable Development and World Ecology; JST: Journal of Sustainable Tourism; GECHPD: Global Environmental Change Human and Policy Dimensions; IJAS: International Journal of Agricultural Sustainability; SS: Sustainability Science; BRI: Building Research and Information; CIT: Current Issues in Tourism; GJ: Geographical Journal; JEM: Journal of Environmental Management; LUP: Land Use Policy; LE: Local Environment; OCM: Ocean Coastal Management.

Regarding the top 20 journals, the journals that dedicate the highest number of their published articles to the topic of SHC are International Journal of Agricultural Sustainability, with just $1.8 \%$ of its articles dedicated to SHC related to sustainability, followed by Local Environment (1.54\%), Sustainability Science $(1.29 \%)$ and Sustainable Development (1.25\%). The rest of the sources dedicate less than $1 \%$ of their publications to this topic. The top three journals dedicate less than $0.50 \%$ of the publications to SHC, a fact that shows the scarcity of research on the topic and its great potential.

The top journals as regards the number of times their articles are cited by the sample documents dealing with SHC related to sustainability are World Development (121.57), Sustainable Development (49.29) and Global Environmental Change Human and Policy Dimensions (43.8). However, the results are significantly affected by the presence of two documents with the highest number of citations in the case of World Development and Sustainable Development. Each of these two journals published seven documents on SHC related to sustainability. Additionally, none of the top five journals have any document with more than 200 citations. 


\subsection{Keywords Analysis}

Keywords analysis focuses on the distribution of the most frequent keywords through keyword co-occurrence (keywords that appear together in the same article). The purpose is to observe and stress the most important topics of research in the field of SHC related to sustainability. In this case, only author keywords below the abstract are considered. The tool counts the number of documents in which two keywords appear together (highlighted by the authors in each document). After considering the 635 SHC-related works, the software VOS viewer indicates the existence of 1990 keywords. Figure 2 presents the main keywords and the size of the nodes: the larger the node and the keyword, the greater the weight; thicker lines mean more frequent co-occurrence; the smaller the distance between the nodes, the stronger the relationship they have. The program indicates with the same color a group of related keywords, or a cluster of keywords. Specifically, the software identifies nine clusters. Using a threshold of five co-occurrences, Figure 2 represents the 53 keywords with the most frequent co-occurrences. The red cluster has the highest number of keywords, led by the word "sustainability", with 11 items, containing also "tourism", "developing countries", "vulnerability" or "poverty"; these words are related purely to sustainability and the quality of life. The second cluster is that led by social capital (in green), with eight items, including also resilience or collaboration, which stress the relevance of group collaboration. Finally, the third and fourth clusters, with six items each, are the ones led by the keywords "social sustainability" (dark blue) (containing community or governance, which stress the relevance of "societal capital") and "sustainable development" (yellow) (which contains intellectual capital or corporate social responsibility, focusing on the ethical part of development). However, the keyword "human capital", which leads the light blue cluster, is the keyword with the third highest occurrence (this cluster stresses its relationship with innovation, entrepreneurship or local development, emphasizing the importance of human capital for sustainability). Table 4 illustrates the top 30 keywords, showing keyword occurrences and co-occurrences linking strengths.

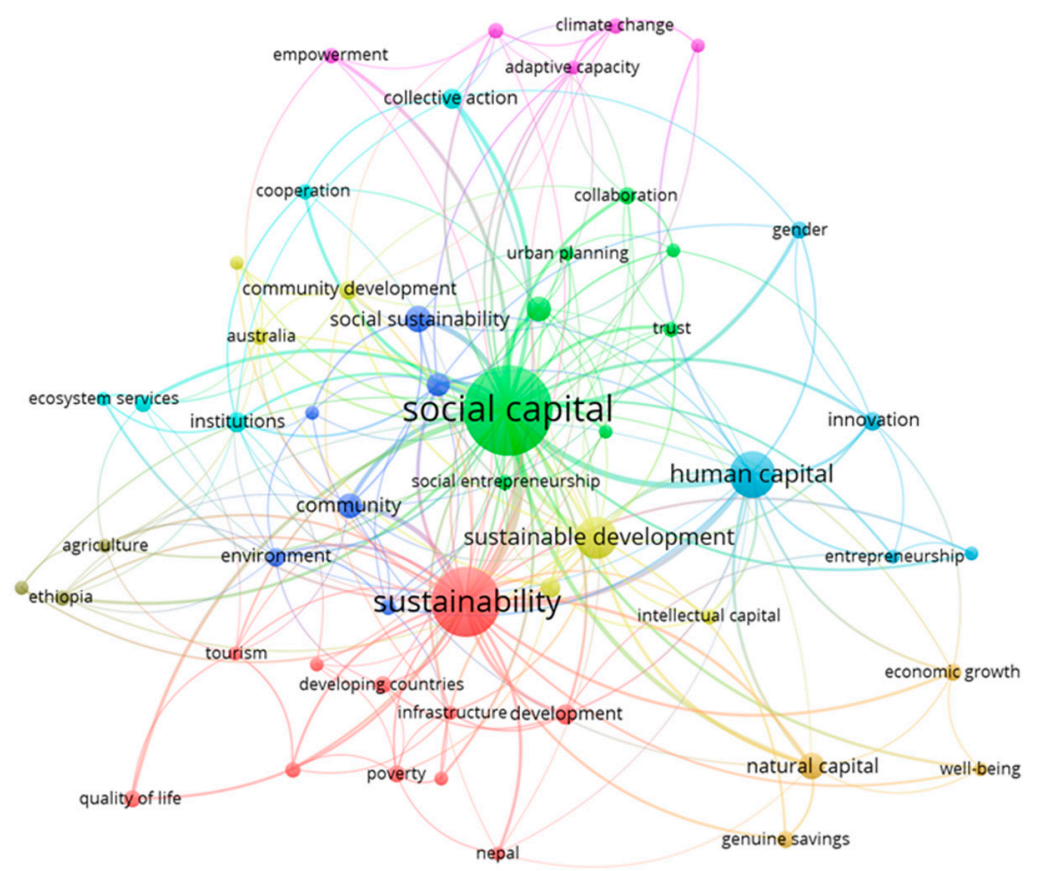

Figure 2. Co-occurrence network of author keywords of SHC-related publications. 
Table 4. The top author keywords co-occurrence of SHC-related publications.

\begin{tabular}{|c|c|c|c|}
\hline Rank & Keyword & Occurrences & Co-Occurrences \\
\hline 1 & Social capital & 193 & 233 \\
\hline 2 & Sustainability & 119 & 146 \\
\hline 3 & Human capital & 52 & 59 \\
\hline 4 & Sustainable development & 42 & 47 \\
\hline 5 & Natural capital & 17 & 31 \\
\hline 6 & Social sustainability & 17 & 16 \\
\hline 7 & Resilience & 16 & 24 \\
\hline 8 & Community & 15 & 27 \\
\hline 9 & Governance & 14 & 23 \\
\hline 10 & Collective action & 11 & 16 \\
\hline 11 & Corporate social responsibility & 11 & 14 \\
\hline 12 & Development & 11 & 11 \\
\hline 13 & Institutions & 10 & 15 \\
\hline 14 & Community development & 9 & 18 \\
\hline 15 & Environment & 9 & 14 \\
\hline 16 & Innovation & 9 & 14 \\
\hline 17 & Australia & 8 & 12 \\
\hline 19 & Collaboration & 8 & 12 \\
\hline 19 & Developing countries & 8 & 8 \\
\hline 20 & Economic growth & 8 & 9 \\
\hline 21 & Gender & 8 & 11 \\
\hline 22 & Poverty & 8 & 10 \\
\hline 23 & Genuine savings & 7 & 6 \\
\hline 24 & Quality of life & 7 & 9 \\
\hline 25 & Rural development & 7 & 11 \\
\hline 26 & Climate change & 6 & 8 \\
\hline 27 & Cooperation & 6 & 10 \\
\hline 28 & Economic development & 6 & 7 \\
\hline 29 & Education & 6 & 9 \\
\hline 30 & Empowerment & 6 & 8 \\
\hline
\end{tabular}

Source: Own elaboration based on WoS 2017. R: Rank; Occurrences: Author keyword occurrences; Co-occurrences: Author keyword co-occurrences link.

\subsection{Reference, Journal and Author Co-Citation Analysis}

This section focuses on co-citation to analyze references, journals, and authors. This kind of analysis observes the simultaneous citation of two items (author, journal, or article) by a third document (two items appear together in the reference list of the same document) [37]. As in the previous analysis, this technique divides bibliometric documents into clusters with network analysis. The tool allows the identification of the relationships, structure, characteristics, and development of SHC related to sustainability, and maps these relationships.

The co-citation of references identifies the main research themes about SHC related to sustainability. Figure 3 shows that two publications by Putnam et al. $(2001,1994)$ were cited 66 and 61 times, respectively, by the 635 SHC documents related to sustainability [41,42]. Thus, these documents lead the ranking. However, the document by Putnam published in 1994 has a higher strength of link than the other [41], with strengths of link of 58 and 54, respectively. The third and fourth most-cited documents are authored by Coleman, with 41 citations each [8,43], followed by that by Pretty and Ward (2001) with 40 citations [5]. However, the third document in the ranking according to strength of link is Pretty and Ward's study (40), followed by two documents by Coleman (with link strength scores of 39 each) [8,43]. These documents also lead the five main clusters. The first of these, in red, comprises 16 items and is led by Putman's studies [42,43], although this cluster also includes Coleman [8] and relevant authors in the area such as Bourdieu [1], Narayan, or an early work by Granovetter [44]. The second cluster, in green, also with 16 cites, is led by studies by Pretty, and includes Ostrom, Hardin or Adger. The third cluster, in blue, is led by the two studies 
by Coleman [8,43], and includes authors related to the resources approach in management such as Wernerfelt, Barney, and Granovetter [45]. Finally, the fourth cluster is more dispersed (yellow), has 10 items, and is led by some documents by Pearce. The fifth cluster has just five items and is led by Fukuyama and Bebbington. The threshold for Figure 3 is 10 citations; this threshold is met by 60 references.

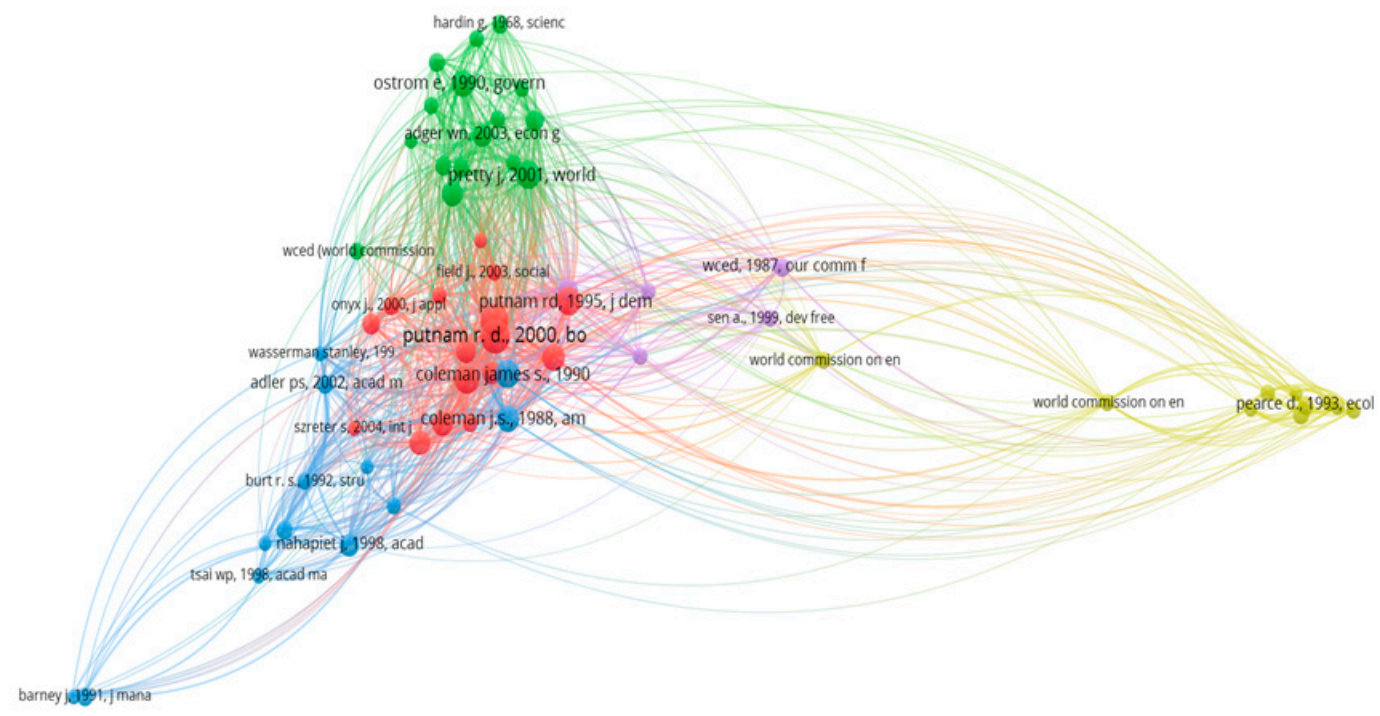

Figure 3. Co-citation of cited references on SHC documents related to sustainability.

The first study by Putman et al. (1994) is a book about democracy that analyzes institutional development and focuses on social capital and institutional success. Putman's 2001 publication is also a book; it deals with the collapse and revival of the American community, and talks about social change in America, political, religious and civic participation, and the importance of informal social connections.

Coleman [8] introduces and explains the concept of social capital. The author describes its relationship with financial capital, physical capital, and human capital and analyzes three of its forms, its determinants and its influence on human capital. Moreover, Coleman [43] analyzes Parson's theory of social institutions and links it to a social theory. Additionally, the study introduces the dimensions of social capital (i.e., interpersonal trustworthiness, cooperation, solidarity, and norms), which depend on civil engagement and on social networks. Finally, the study by Pretty and Ward [5] analyzes the way social and human capital affects environmental outcomes and identifies four relevant aspects: (1) relations of trust; (2) reciprocity and exchanges; (3) common rules, norms, and sanctions; and (4) connectedness, networks, and groups.

The following co-citation analysis focuses on the journal co-citation network of SHC studies related to sustainability (Figure 4). The figure includes 161 main journals, 15,813 sources cited by the 635 documents regarding SHC. The threshold is 25 citations. The size of a node in this analysis reveals the activity of the journal, measured by the number of published articles, and the distance between two sources indicates citation frequency. The VOS viewer identifies five main clusters. As to the sources, the results show that World Development is the journal with most citations (446) and the highest strength of link (9142), followed by Ecological Economics (394 citations and 8381 strength of link), Ecology and Society (234 citations, 7535 strength of link), Academy of Management Review (238 citations, 7225 strength of link) and Science (253 citations, 6509 strength of link). The top ten journals according to strength of link are led by Academy of Management Journal (164 citations, 5820 strength of link), Journal of Business Ethics (222 citations, 5310 link strength), Global Environmental Change-Human and Policy Dimensions (175 citations, 4987 link strength), Strategic Management Journal (124 citations, 4269 link strength) and American Economic Review (177 citations, 4172 link strength). The program reveals that all the main 
journals are divided into five main clusters. The red cluster has the most items (48) and is in the center of the picture. This cluster includes sources such as American Journal of Sociology, Journal of Clean Production, Journal of Rural Studies, and Social Science and Medicine. All of these are important journals, but none are among the top 10 journals with most citations. This cluster has a multidimensional nature. The second cluster, in green, comprises 48 items, is led by World Development, and includes Ecology and Society, Science, and Global Environmental Change-Human and Policy Dimensions, all of which are among the top journals according to strength of link. This cluster is related to ecology, environment, and the management of natural resources. The third cluster, in blue, includes 31 items and relevant sources such as Academy of Management Review, Academy of Management Journal, Journals of Business Ethics, or Strategic Management Journal, all of which are among the top three journals according to strength of link. This cluster is related to management. The fourth cluster, in yellow, comprises 28 items and is led by Ecological Economics, which ranked second in number of citations and strength of link, and American Economic Review, also among the top journals. This cluster focuses on economics. Finally, the last cluster, in purple, focuses on tourism and comprises only six journals (Annals of Tourism Research, Tourism Management, Journals of Sustainable Tourism, or Journal of Travel Research), although none of these are among the top journals according to the previously mentioned classification.

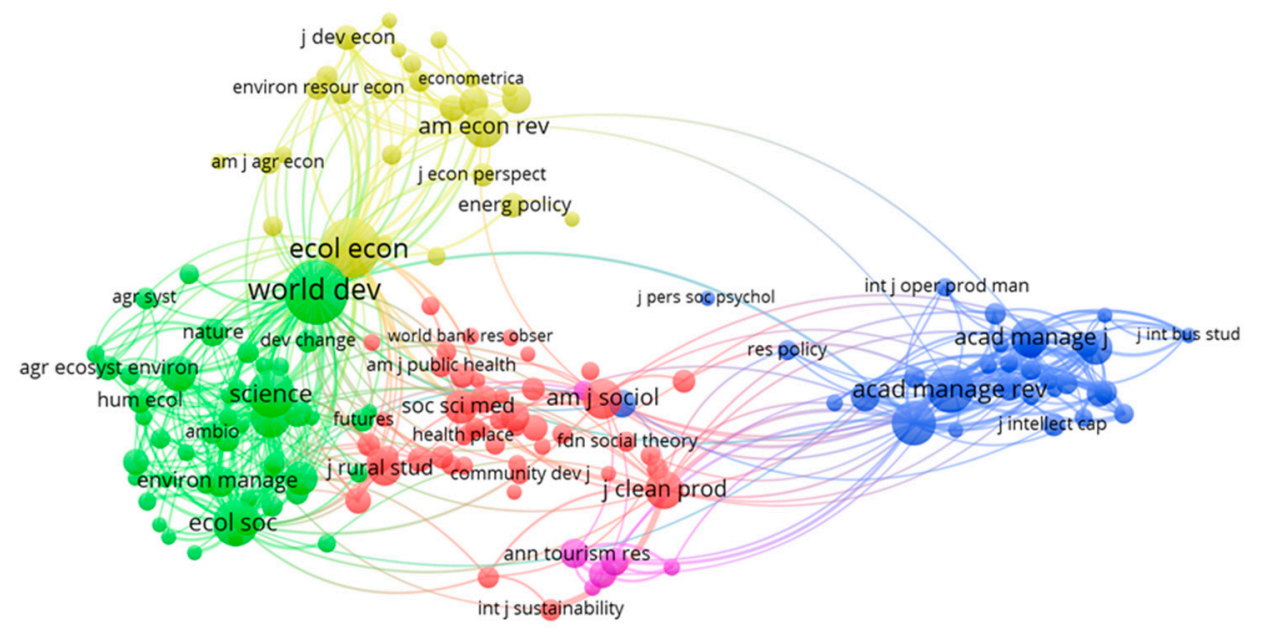

Figure 4. Journal co-citation network on SHC related to sustainability.

The following co-citation analysis focuses on the network of the main authors. Figure 5 presents the results of the analysis, which include five clusters that comprise 68 authors, out of the 21,301 cited. The threshold is 20 citations. Regarding the number of authors, the first cluster is in red, on the left-hand side of the figure, and comprises 21 items. The second, in green and on the right side of the figure has 16 items. The third cluster by number of components is in blue; it comprises 13 authors. The fourth cluster, with 11 authors, is in yellow, at the top of the figure. Finally, the fifth cluster, in purple, contains only 6 items. Nevertheless, from a citation perspective, the main cluster is the red one. This cluster is led by Putnam, the author with the highest number of citations (236) and with the highest strength of link (2015.52). The red cluster also includes three other authors that are among the top 10 authors according to the citation or strength of link criteria. These authors are Coleman (125 citations, 123.02 strength of link), which ranked third on the list and Woolcock (70 citations, 67.01 link strength) and Bourdieu (71 citations, 63.97 link strength), who ranked sixth and seventh, respectively, according to the link strength criterion. This cluster also includes Fucuyama, also among the top 20 authors. Therefore, the red cluster focuses on sociology. The second most important cluster, according to the citation criterion, is the yellow one. This cluster includes Ostrom, the second most-cited author (179 citations, 142.7 link strength), and three other authors included among the top 10 authors in this list-Berkes (72 citations, 93.65 link strength), Folke (67 citations, 61.83 link strength), Adger (70 citations, 60.56 link strength)—and Agrawal and Holling, who are 
among the 20 most-cited authors. The results show that Ostrom, Berkes, and Folke have some studies in common. Moreover, the main areas of this cluster include socio-ecological and environmental areas, and economic, strategic planning and growth views, which include institutional diversity and self-organization related to sustainability issues. Near the yellow cluster, the blue cluster includes the fourth most-cited author, Pretty, with 116 citations and 101.17 link strength. This cluster also includes Chambers, who is among the top 20 authors, and Bebbington. The most important work by Pretty related to our area is titled "Social capital and the environment" [4]. This title, a review of its diverse works, and the close relationship with the yellow cluster, stress the environmental perspective of this cluster. The green cluster, on the right side of the figure, contains 16 authors. This cluster only has the World Bank (116 citations, 95.07 link strength) among the top 10 authors; however, it includes Hamilton, Dasgupta, Pearce, Costanza, who are among the top 20 authors. Finally, the purple cluster, located between the green and the red cluster, includes Portes and the OECD as authors among the top 20 , but far from the 10 main ones.

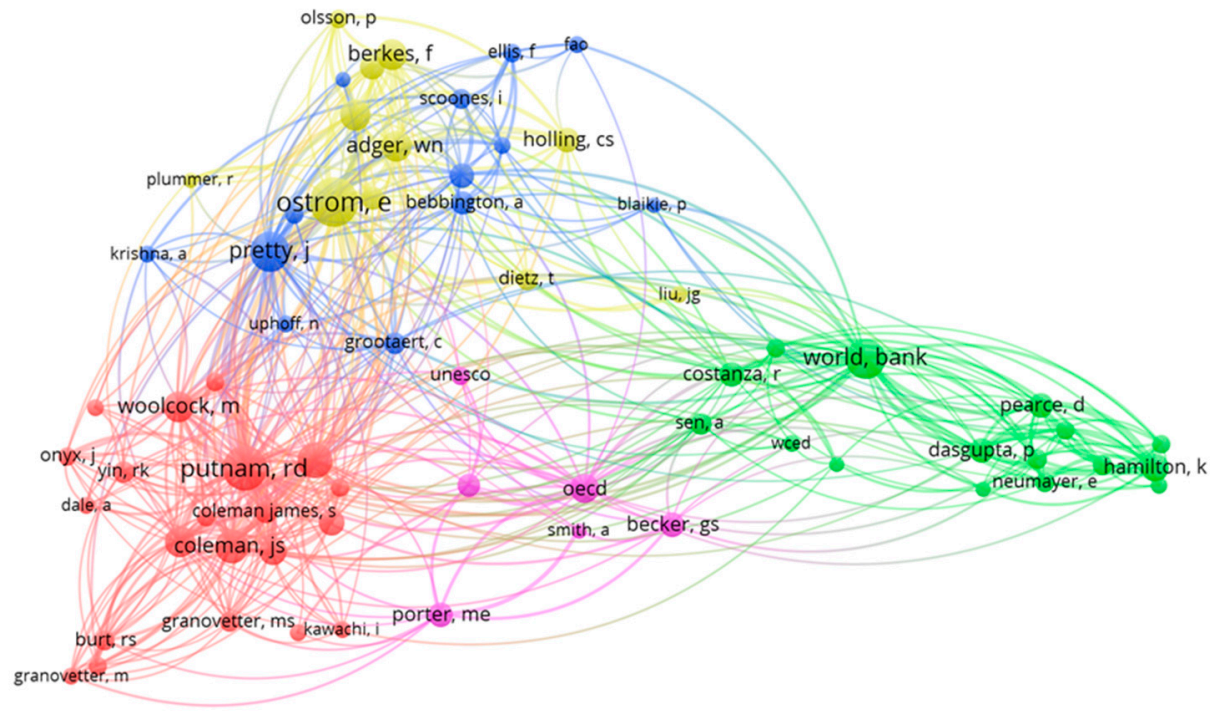

Figure 5. Author co-citation network on SHC related to sustainability.

\subsection{Country and University Co-Author Analysis}

The last analysis focuses on co-authorship. The analysis allows the examination of the structure of research collaboration networks in a specific area. In this sense, co-authorship analysis shows the behavior of research teams, and their network of relationships [46]. In this analysis, the nodes represent influential countries or institutions. In addition, the thickness and distance between two nodes represents the degree of collaboration [16]. Two co-authorship analyses are performed: analysis of countries and an analysis of institutions.

Regarding countries, the VOS viewer displays the networks among nations. Specifically, the analysis reveals the relatively low research dispersion.

The USA and England, the most-commonly referenced countries, are in the center of Figure 6. A more detailed analysis of the results reveals that the USA (173 documents, 4199 citations), and England (87 documents, 2643 citations) lead the classification and the blue cluster. This cluster comprises seven countries and includes the Netherlands (30 documents, 375 citations, the sixth country according to the link strength criterion), China (155 documents, also placed in the 20 top countries) and Italy, which, despite being outside the top countries according to link strength, published 26 papers. The second cluster, also with seven countries, in green, is led by Australia ( 74 documents, 1004 citations), and includes India (16 documents, 133 citations), which is among the top 10 countries according to link strength, and Scotland (16 documents), New Zealand (15 documents), and Norway (8 documents), which are also among the top 20 countries according to link strength. The third cluster of countries, 
in red, comprises seven countries and is led by Germany (29 documents, 197 citations), the fifth country according to the link strength criterion. This cluster, which is associated with Northern Europe and South America, includes Switzerland (15 documents, 353 citations), which is among the top 10 countries according to link strength, and France (14 documents), and Brazil (12 documents), which are among the top 20 countries. The fourth cluster, the most dispersed one and with a lower connection to the others, is the yellow cluster. With six countries, the yellow cluster does not include any of the top 10 countries regarding link strength, although it includes Japan (15 documents), South Africa (22 documents), and Bangladesh ( 6 documents), which are among the top 20 countries. The fifth cluster, in purple, comprises four countries and is led by Spain ( 28 documents, 403 citations) and Sweden (18 documents, 1861 citations), the only two countries in this cluster among the top 10 countries regarding link strength, and Chile (six documents). Finally, the sixth cluster, in light blue, contains three countries and is led by Canada (34 documents, 491 citations), the only country in this cluster that is included in the top 10 countries.

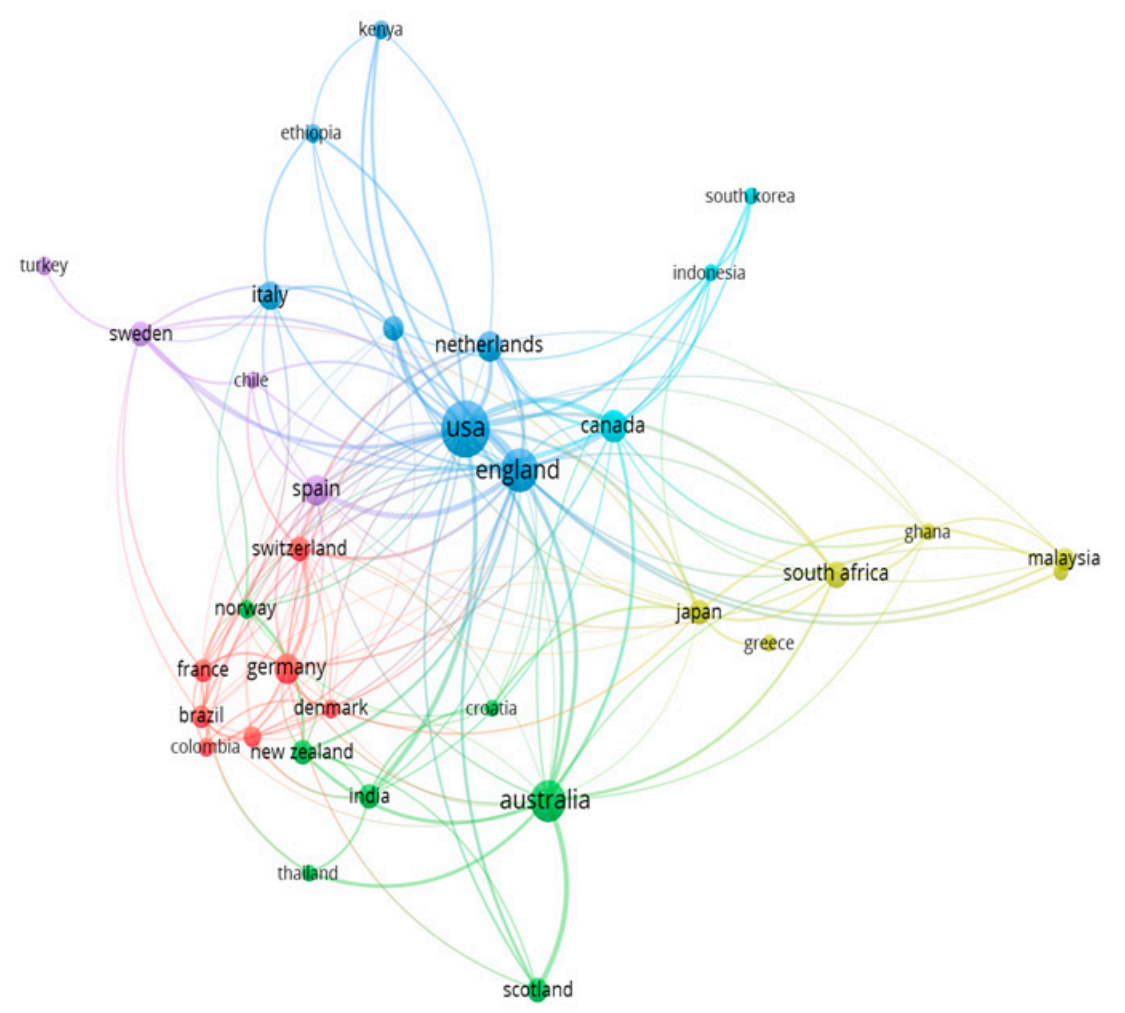

Figure 6. Countries co-authorship network of SHC related to sustainability.

The figure represents the 34 countries (out of 95 nations) that meet the threshold of five documents. The second co-authorship analysis focuses on the most influential institutions regarding SHC related to sustainability (Figure 7). The figure includes 42 organizations, out of 851 . The minimum number of documents for inclusion is four. In this ranking, the 10 leading universities, according to the link strength criterion, are Washington State university (seven documents, 168 citations), University of Kansas (six documents, 44 citations), Arizona State University (four documents, 27 citations), La Trobe University (five documents, 53 citations), Monash University (five documents, 68 citations), University of California Berkeley (five documents, 64 citations), University of Michigan (four documents, 54 citations), McGill University (five documents, 18 citations), University of Aberdeen (four documents, 101 citations), and University of Amsterdam (five documents, 33 citations). Other relevant institutions are London School of Economics and Political Science, University of Maryland, University of Stirling University of Washington, Columbia University, and Erasmus University, James Cook University, Michigan State University, and Massachusetts Institute of Technology (MIT). The program reveals four 
main clusters of universities. On the left side of the picture, we can find, in red, University of British Columbia, Erasmus University, and Massachusetts Institute of Technology, together with Arizona State University. On the right-hand side, and opposite the previous cluster, we find Columbia University and University of Washington, in green. The blue cluster includes University of California Berkeley and University of Michigan, whereas the yellow cluster comprises McGill University and University of Maryland.

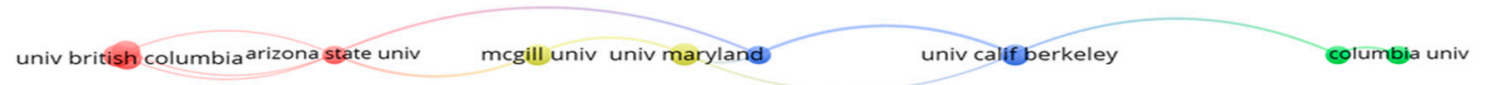

Figure 7. Institutions' co-authorship network regarding SHC research related to sustainability.

\section{Discussion and Conclusions}

This study analyzes the relevance of SHC and the research that combines SHC with sustainability through the use of bibliometrics. In addition, it overviews previous bibliometric analyses related to social capital and human capital, or the combination of both concepts. Nevertheless, this study covers a research gap by addressing the evolution of social capital and human capital in areas related to sustainability and by presenting the results visually.

The results lead to the following conclusions. Firstly, the analysis of the definition of social capital and human capital evinces not only the debate about the terms, due to their complexity, but also the relevance of both concepts, especially for the topic of sustainability. The relevance of SHC capital does not reside only in its role for knowledge creation and development for firms, but also in its crucial effect on the promotion of sustainable policies (economic, social, or even environmental) that can affect organizations and diverse environments. Understanding these mechanisms is essential for managers and practitioners, but also for researchers.

Research on sustainability has experienced huge growth in recent years, with over 10,000 documents published annually since 2015. This increase is reflected in the literature on SHC. However, this study shows that the literature on SHC is scarce, but very diverse, and that diversity of perspectives defines its high potential. This study represents the first attempt to analyze SHC research related to sustainability. The results show that the scarcity of research on SHC related to sustainability is even more significant regarding research on financial capital, economic capital and natural capital, which impeded an analysis through bibliometric techniques to compare its intrinsic features. Moreover, the different approaches to SHC (and natural, financial and economic capital) are essential to develop sustainable policies that contemplate the diversity of the process. Although the lack of enough literature can be an obstacle for a proper management of diverse situations, it also offers an opportunity to develop the literature. In this vein, this study is the starting point for further analyses about these topics.

Nevertheless, the high number of citations received by the main documents reflects the relevance of the topic. For instance, the most-cited document in sustainability has a little more than 4100 citations, and another document that focuses on SHC aspects related to sustainability has more than 1700 citations [29]. In addition, two other documents have more than 500 citations, and more than 20 documents have more than 10 citations. The citations per year also indicate the importance of the topic. The study by Folke et al. (2005) is the most influential and cited document according to the citations per year (142.67 citations per year) [29]. In addition, five of the 10 most influential documents have received over 30 citations per year.

The 635 documents on SHC related to sustainability were published in 436 journals, which indicates the simultaneous development of the topic across different academic disciplines. However, the main category is environmental studies, with more than $20 \%$ of the documents published. In addition, the top sources of publication in the field are Sustainability, Ecological Economics, and Journal of Cleaner Production, accumulating more than $9 \%$ of publications. However, none of the 20 top journals dedicate to this topic more than $2 \%$ of their published articles, the most prolific being the 
International Journal of Agricultural Sustainability, followed by World Development, with publications on this topic receiving more than 120 citations on average.

The keywords co-occurrence reveals that the main subjects on SHC related to sustainability belong to four main areas, two related to sustainability, and two related to social and human capital. Hence, the most frequent keywords are social capital, sustainability, human capital, and sustainable development. This analysis also stresses the close relationship with other areas, such as natural capital (fourth in the list of co-occurrences), and the importance of resilience, community, or governance and development. Specifically, the main words that are connected to social capital in the same cluster are words like resilience, trust, social entrepreneurship, urban planning, collaboration, or environmental management. This fact, together with the close relationship of "social capital" with "governance" in the Figure 2, indicates the crucial importance of the social structures or networks, and the relevance of collaboration to secure benefits and enhance sustainability, as mentioned by Portes [3] in its definition of social capital. In addition, the strong relationship among human capital and words such as "entrepreneurship" and "innovation", and also the central situation of the words "social entrepreneurship" and "resilience" implicates the need for focusing on entrepreneurial actions related to sustainability, and the need to empower the actions of individual people (mainly women, as shown in the connection between gender and human capital) as essential mechanisms to overcome difficult situations and promote sustainability. On the other hand, the co-citation analysis indicates that two articles by Putnam [41,42] lead the ranking of the most-cited documents of the 635 articles related to SHC and sustainability. These articles are followed by two other articles by Coleman $[8,43]$. The four articles are also central in the network of other documents. Another important cluster is led by articles by Pretty and Ward [5].

Focusing on the journal co-citation network, the results reveal five clusters of journals. The leader is World Development, which leads a cluster of journals related to ecology, the environment, and the management of natural resources. However, the cluster with the most journals, which is central in the picture, has a multidisciplinary nature. Other important clusters have managerial (with journals such as Academy of Management Review, Academy of Management Journal, Journals of Business Ethics, or Strategic Management Journal), economic (with journals such as Ecological Economics, or American Economic Review) or tourism perspective (with journals such as Annals of Tourism Research, Tourism Management, Journals of Sustainable Tourism, or Journal of Travel Research). This analysis reveals the prominence of economic and managerial areas in this topic, but also this area's multidisciplinary nature, which can be a source of further research using alternative approaches. The results also stress the relevance of the tourism sector in the literature related to social and human capital

The author co-citation analysis yields five clusters of authors. The main cluster is led by Putnam, the author with the highest number of citations and includes authors such as Coleman or Bourdieu, who follow a sociological perspective. The second cluster, led by Ostrom and some of her co-authors, follows a more economic, strategic planning and an institutional perspective. The cluster led by Pretty has a more environmental perspective. Other clusters include institutional documents coming, for instance, from the World Bank or the OECD.

The co-authorship analysis of SHC documents related to sustainability identifies five nodes of countries, led by the USA, Australia, Canada, Germany and Spain. Finally, the leading universities come from the USA, with Washington State University, University of Kansas and Arizona State in first position; other universities from England and Australia are also well placed. In this vein, the study has mapped the research dimensions of SHC related to sustainability, and their relative importance and the evolution of the different perspectives. These results are important for policymakers and practitioners when considering sustainable polices. The research results indicate the main perspectives that they can take into account when planning to develop sustainable policies focused on organizations, institutions or locations. In addition, policymakers may use the results to develop further policies that take into account the complexity of the topic from a managerial, sociological, or environmental perspective.

On another note, the results show a lack of research on information and communication technologies' effect on SHC development, the development of new techniques and solutions, and 
sustainability issues [47], and their impact on sustainability. The results do not indicate extensive research on collaborative economy, open innovation and crowdsourcing processes [16] in the development of SHC and their impact on sustainability; however, keywords such as "cooperation", "collaboration" or "collective action" indicate the relevance of the topic. Finally, regarding ethics and socially responsible polices, or the promotion of social entrepreneurship [48], incipient keywords such as "community development", "rural development", "corporate social responsibility", "education", or "empowerment" indicate new questions that can be developed soon, and that must be taken into account by institutions and organizations.

The results are particularly relevant for researchers, who may use the connections between the diverse areas analyzing SHC related to productivity to develop new ideas and studies in areas that are still underdeveloped. Furthermore, the new and growing approaches may open new research avenues. For instance, the most studied approaches (i.e., environmental studies, sociology, management and economics) could be complemented with new areas as indicated by a multidimensional cluster that comprises a plethora of scarcely employed perspectives. This study is also useful for the analysis of financial capital, economic capital, and natural capital related to sustainability, which are areas with great potential.

Future research may use a theoretical approach that combines various perspectives or a methodological approach for the development of indicators to measure the concepts explained. This bibliometric analysis may also offer answers to crucial questions associated with each research area [16] and help to discover the determinants of the evolution of research. In this vein, new trends of research are motivated by three main reasons [16]: the expansion of the topic, the development of new sciences or areas of study, and the emergence of fashionable questions in research or society. For instance, the keywords "social entrepreneurship", or "indicators", which are quite central in the keyword concurrence analysis, indicate that these questions, although incipient, are especially important in the area of social and human capital related to sustainability. Moreover, the growing evolution of SHC related to sustainability, the important number of citations of the main documents in this area, or the still scarce analysis of diverse perspectives (such as marketing, medicine, computing ethics, or even psychology) indicate an important potential for further research. In this respect, this bibliometric analysis has shown numerous perspectives that are misleading, which can also help researchers for further analysis.

Despite being a pioneer as regards the topic of research, this study is not without limitations, some of which are good opportunities for further research. First of all, the use of a purely objective technique, the collection of keywords, may lead to confusing interpretations if it is not complemented with qualitative analyses. In this case, the relatively small sample of documents analyzed could limit the interpretation of the results. Secondly, this study focuses on the material provided by the WoS Core Collection database, and limits the sample to articles, reviews, letters, and notes. This procedure can help to guarantee the inclusion of the most important and consistent works; however, further research could use other materials, such as conference proceedings, or other reports, such as doctoral theses. This study could be also be extended with the use of other sources such as Scopus, or material in languages other than English. In this respect, the co-authorship of institutions and countries shows the prevalence of USA and Anglo-Saxon countries at a level that indicates the lack of representation of important countries such as Russia, India, or China. The software used in this study and other bibliographic tools, software and methodologies could improve or extend the conclusions. Finally, future research could apply a qualitative approach to the analysis of the identified clusters.

Author Contributions: Conceptualization, F.J.G.-S.; Methodology, F.J.G.-S. \& T.F.G.-C.; Software, F.J.G.-S.; Validation, F.J.G.-S., M.D.B.-C. \& T.F.G.-C.; Formal Analysis, F.J.G.-S.; Investigation, F.J.G.-S. \& T.F.G.-C.; Resources, T.F.G.-C.; Data Curation, F.J.G.-S. \& T.F.G.-C.; Writing-Original Draft Preparation, F.J.G.-S.; Writing-Review E Editing, M.D.B.-C.; Visualization, T.F.G.-C. \& M.D.B.-C.; Supervision, T.F.G.-C.; Project Administration, T.F.G.-C.; Funding Acquisition, T.F.G.-C.

Funding: This research was funded by Catedra de Empresa y Humanismo de la Universidad de Valencia grant number 3050361465. 
Conflicts of Interest: The authors declare no conflict of interest. The founding sponsors had no role in the design of the study; in the collection, analyses, or interpretation of data; in the writing of the manuscript, and in the decision to publish the results.

\section{References}

1. Bourdieu, P. The forms of capital. In Handbook of Theory and Research for the Sociology of Education; Richardson, J.G., Ed.; Greenwood: New York, NY, USA, 1985; pp. 241-258, ISBN1 0313235295, ISBN2 9780313235290.

2. Baker, W.E. Market networks and corporate behavior. Am. J. Sociol. 1990, 96, 589-625. [CrossRef]

3. Portes, A. Social capital: Its origins and applications in modern sociology. Annu. Rev. Sociol. 1998, 24. [CrossRef]

4. Falk, I.; Kilpatrick, S. What is social capital? A study of interaction in a rural community. Sociol. Rural. 2000, 40, 87-110. [CrossRef]

5. Pretty, J.; Ward, H. Social capital and the environment. World Dev. 2001, 29, 209-227. [CrossRef]

6. Kizos, T.; Plieninger, T.; Iosifides, T.; García-Martín, M.; Girod, G.; Karro, K.; Palang, H.; Printsmann, A.; Shaw, B.; Julianna, N.; et al. Responding to landscape change: Stakeholder participation and social capital in five European landscapes. Land 2018, 7, 14. [CrossRef]

7. Gallo, M.; Pezdevšek Malovrhb, S.; Laktićc, T.; De Meoa, I.; Palettod, A. Collaboration and conflicts between stakeholders in drafting the Natura 2000 Management Programme (2015-2020) in Slovenia. J. Nat. Conserv. 2018, 42, 36-44. [CrossRef]

8. Coleman, J.S. Social capital in the creation of human capital. Am. J. Sociol. 1988, 94, 95-120. [CrossRef]

9. Galunic, C.D.; Anderson, E. From security to mobility: Generalized investments in human capital and agent commitment. Organ. Sci. 2000, 11. [CrossRef]

10. Popov, E.; Vlasov, M. Assessment of Intellectual Development of the Human Capital of Hi-Tech Productions. Montenegrin J. Econ. 2018, 14, 121-131. [CrossRef]

11. Palacios-Marqués, D.; Garrigós-Simón, F.J. Validating and measuring IC in the biotechnology and telecommunication industries. J. Intellec. Cap. 2003, 4, 332-347. [CrossRef]

12. Palacios Marqués, D.; Garrigós-Simón, F.J. The effect of knowledge management practices on firm performance. J. Knowl. Manag. 2006, 10, 143-156. [CrossRef]

13. Pretty, J. Agricultural sustainability: Concepts, principles and evidence. Philos. Trans. R. Soc. B 2008, 363, 447-465. [CrossRef] [PubMed]

14. Bebbington, A.; Perreault, T. Social capital, development, and access to resources in highland Ecuador. Econ. Geogr. 1999, 75, 395-418. [CrossRef]

15. Broadus, R. Toward a definition of "bibliometrics". Scientometrics 1987, 12, 373-379. [CrossRef]

16. Garrigos-Simon, F.J.; Narangajavana-Kaosiri, Y.; Lengua-Lengua, I. Tourism and Sustainability: A Bibliometric and Visualization Analysis. Sustainability 2018, 10, 1976. [CrossRef]

17. Diem, A.; Wolter, S.C. The use of bibliometrics to measure research performance in education sciences. Res. High. Educ. 2013, 54, 86-114. [CrossRef]

18. Liao, H.; Tang, M.; Luo, L.; Li, C.; Chiclana, F.; Zeng, X.J. A bibliometric analysis and visualization of medical big data research. Sustainability 2018, 10, 166. [CrossRef]

19. Rost, K.; Teichert, T.; Pilkington, A. Social network analytics for advanced bibliometrics: Referring to actor roles of management journals instead of journal rankings. Scientometrics 2017, 112, 1631-1657. [CrossRef]

20. Lee, C.-J.; Sohn, D. Mapping the social capital research in communication: A bibliometric analysis. J. Mass Commun. Q. 2016, 93, 728-749. [CrossRef]

21. Shen, Y. A literature analysis of social capital's transnational diffusion in Chinese sociology. Curr. Sociol. 2016, 64, 815-832. [CrossRef]

22. Pezzoni, M.; Sterzi, V.; Lissoni, F. Career progress in centralized academic systems: Social capital and institutions in France and Italy. Res. Policy 2012, 41, 704-719. [CrossRef]

23. Huo, A.Y. Bibliometric Study of Specific Human Capital-Based on the CNKI Series Data Analysis from 2000 to 2014. ACSR-Adv. Comput. Sci. Res. 2017, 75, 70-79.

24. Erkens, M.; Paugam, L.; Stolowy, H. Non-financial information: State of the art and research perspectives based on a bibliometric study. Comptabilité-Contrôle-Audit 2015, 21, 15-92. [CrossRef] 
25. Ponomariov, B.L.; Boardman, P.C. Influencing scientists' collaboration and productivity patterns through new institutions: University research centers and scientific and technical human capital. Res. Policy 2010, 39, 613-624. [CrossRef]

26. Goudard, M.; Lubrano, M. Human capital, social capital and scientific research in Europe: An application of linear hierarchical models. Manch. Sch. 2013, 81, 876-903. [CrossRef]

27. Melkers, J.; Kiopa, A. The social capital of global ties in science: The added value of international collaboration. Rev. Policy Res. 2010, 27, 389-414. [CrossRef]

28. Klenk, N.L.; Hickey, G.M.; Maclellan, J.I. Evaluating the social capital accrued in large research networks: The case of the Sustainable Forest Management Network (1995-2009). Soc. Stud. Sci. 2010, 40, 931-960. [CrossRef]

29. Folke, C.; Hahn, T.; Olsson, P.; Norberg, J. Adaptive governance of social-ecological systems. Annu. Rev. Environ. Resour. 2005, 30, 441-473. [CrossRef]

30. Merigó, J.M.; Yang, J.B. Accounting research: A bibliometric analysis. Aust. Account. Rev. 2017, $27,71-100$. [CrossRef]

31. Delgado López-Cózar, E.; Robinson-García, N.; Torres-Salinas, D. The Google Scholar experiment: How to index false papers and manipulate bibliometric indicators. J. Assoc. Inf. Sci. Technol. 2014, 65, 446-454. [CrossRef]

32. Cancino, C.; Merigó, J.M.; Coronado, F.; Dessouky, Y.; Dessouky, M. Forty years of Computers \& Industrial Engineering: A bibliometric analysis. Comp. Ind. Eng. 2017, 113, 614-629. [CrossRef]

33. Blanco-Mesa, F.; Merigó, J.M.; Gil-Lafuente, A.M. Fuzzy decision making: A bibliometric-based review. J. Intell. Fuzzy Syst. 2017, 32, 2033-2050. [CrossRef]

34. Merigó, J.M.; Gil-Lafuente, A.M.; Yager, R.R. An overview of fuzzy research with bibliometric indicators. Appl. Soft Comp. 2015, 27, 420-433. [CrossRef]

35. Hirsch, J.E. An index to quantify an individual's scientific research output. Proc. Natl. Acad. Sci. USA 2005, 102, 16569-16572. [CrossRef] [PubMed]

36. Van Eck, N.J.; Waltman, L. Software survey: VOSviewer, a computer program for bibliometric mapping. Scientometrics 2010, 84, 523-538. [CrossRef] [PubMed]

37. Small, H. Co-citation in the scientific literature: A new measure of the relationship between two documents. J. Am. Soc. Inf. Sci. 1973, 24, 265-269. [CrossRef]

38. Chisti, Y. Biodiesel from microalgae. Biotechnol. Adv. 2007, 25, 294-306. [CrossRef]

39. Bebbington, A. Capitals and capabilities: A framework for analyzing peasant viability, rural livelihoods and poverty. World Dev. 1999, 27, 2021-2044. [CrossRef]

40. Pretty, J. Social capital and the collective management of resources. Science 2003, 302, 1912-1914. [CrossRef]

41. Putnam, R.D. Bowling Alone: The collapse and Revival of American Community; Simon and Schuster: New York, NY, USA, 2001; ISBN 0743203046.

42. Putnam, R.D.; Leonardi, R.; Nanetti, R.Y. Making Democracy Work: Civic Traditions in Modern Italy; Princeton University Press: Princeton, NJ, USA, 1994; ISBN 9780691037387.

43. Coleman, J.S. Commentary: Social institutions and social theory. Am. Sociol. Rev. 1990, 55, 333-339. [CrossRef]

44. Granovetter, M.S. The strength of weak ties. Am. J. Sociol. 1973, 1370-1380. [CrossRef]

45. Granovetter, M. Economic action and social structure: The problem of embeddedness. Am. J. Sociol. 1985, 91, 481-510. [CrossRef]

46. Reyes-Gonzalez, L.; Gonzalez-Brambila, C.N.; Veloso, F. Using co-authorship and citation analysis to identify research groups: A new way to assess performance. Scientometrics 2016, 108, 1171-1191. [CrossRef]

47. Garrigos-Simon, F.J.; Lapiedra Alcami, R.; Barbera Ribera, T. Social networks and Web 3.0: Their impact on the management and marketing of organizations. Manag. Decis. 2012, 50, 1880-1890. [CrossRef]

48. Narangajavana, Y.; Gonzalez-Cruz, T.; Garrigos-Simon, F.J.; Cruz-Ros, S. Measuring social entrepreneurship and social value with leakage. Definition, analysis and policies for the hospitality industry. Int. J. Entrep. Innov. Manag. 2016, 12, 911-934. [CrossRef]

(C) 2018 by the authors. Licensee MDPI, Basel, Switzerland. This article is an open access article distributed under the terms and conditions of the Creative Commons Attribution (CC BY) license (http:/ / creativecommons.org/licenses/by/4.0/). 